\title{
GOOD $\lambda$-INEQUALITIES AND REARRANGEMENT INEQUALITIES FOR VECTOR-VALUED MARTINGALES
}

\author{
YANBO REN
}

Abstract. In this paper, we obtain some good $\lambda$-inequalities and rearrangement inequalities for vector-valued martingales, which are closely related to the geometric properties of the underlying Banach space. In particular, our results extend some important inequalities in classical martingale $H_{p}$ theory, and we establish a relationship between the good $\lambda$-inequality and the rearrangement inequality for some vector-valued martingale function pairs.

Mathematics subject classification (2010): Primary 60G42; Secondary 46E45.

Keywords and phrases: Martingale, good $\lambda$-inequality, rearrangement inequality, $p$-uniformly smooth space, $q$-uniformly convex space.

\section{REFERENCES}

[1] R. J. Bagby, D. S. KurtZ, A rearranged good $\lambda$-inequality, Trans. Amer.Math. Soc., 293 (1986), $71-81$.

[2] C. Bennet, R. Sharply, Interpolation of operators, Academic Press, Boston, 1988.

[3] D. L. Burkholder, Distribution function inequalities for martingales, Ann. Probab., 1 (1973), 19 42.

[4] P. D. LiU, Martingales and geometry of Banach spaces, Science Press, Beijing, 2007.

[5] R. L. Long, Martingale spaces and inequalities, Peking Univ Press, Beijing, 1993.

[6] R. L. Long, Rearrangement techniques in martingale setting, Illinois J. Math., 35 (1991), 506-521.

[7] G. PISIER, Martingales with values in uniformly convex spaces, Israel J. Math., 20 (1975), 326-350.

[8] F. WeIsz, Martingale Hardy spaces and their applications in Fourier analysis, Lecture Notes in Math., Vol. 1568, 1994.

[9] W. A. WoycZYOSKI, Geometry and martingales in Banach spaces, Lecture Notes in Math., Vol. 472, 1975. 